\title{
MAXIMAL OPTIMAL BENEFITS OF DISTRIBUTED GENERATION USING GENETIC ALGORITHMS
}

\author{
A. A. Abou El-Ela, \\ S. M. Allam \\ M. M. Shatla \\ Electrical Engineering Department, Faculty of \\ Engineering, Minoufiya University, Egypt \\ West Delta Regional Control Center, \\ Egyptian Electricity Transmission Co., Egypt
}

\begin{abstract}
As a result of the renewed interest for the distributed power generation (DG); meanly because of the constraints on the traditional power generation besides the great development in the DG technologies, increasing amounts of DG are being used. To accommodate this new type of generation, the existing network should be utilized and developed in an optimal manner. This paper presents an optimal proposed approach to determine the optimal sitting and sizing of DG with multi-system constraints to achieve a single or multi-objectives using genetic algorism (GA). The Linear Programming (LP) is used not only to confirm the optimization results obtained by GA but also to investigate the influences of varying ratings and locations of DG on the objective functions. The methodology is implemented and tested on a real section of the West Delta subtransmission network, as a part of Egypt network. Results are presented, demonstrating that the proper sitting and sizing of DG are important to improve the voltage profile, increase the spinning reserve, reduce the power flow in critical lines and reduce the system power losses.

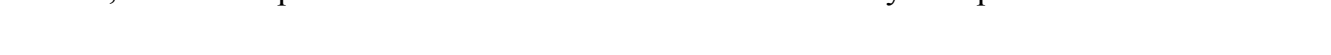

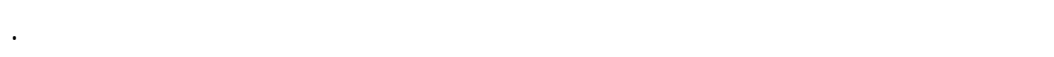

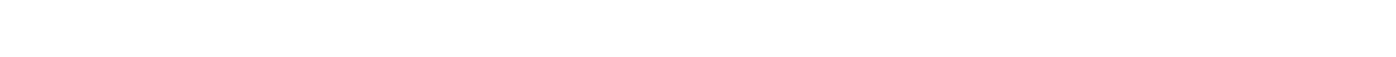

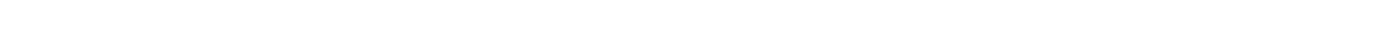

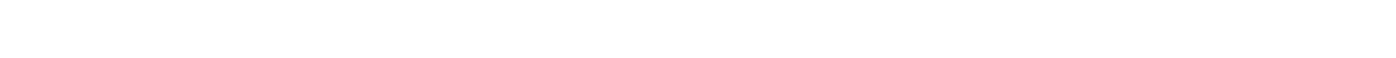

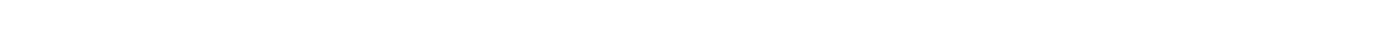

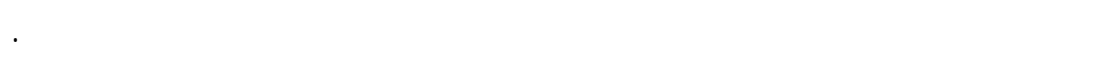

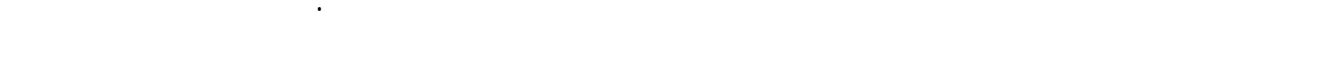

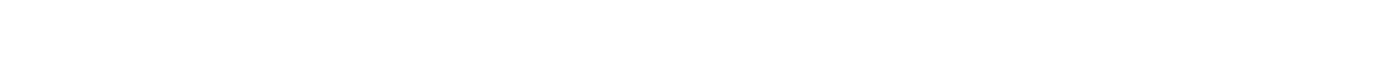

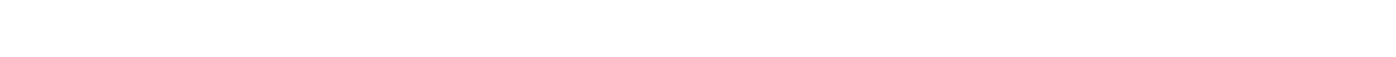

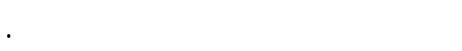

Keywords: Distributed power generation, Genetic algorithm, Leaner programming, Voltage profile improvement, Spinning reserve increasing, Line loss reduction and Line flow reduction.
\end{abstract}

\section{INTRODUCTION}

\subsection{General}

A study by the Electric Power Research Institute (EPRI) indicates that by $2010,25 \%$ of the new generation will be distributed; and a study by the Natural Gas Foundation concluded that this figure could be as high as $30 \%$ [1].

Some of the reasons for an increasing share of DG in different countries has summarized in [2].

\subsection{DG Definition, Issues and Benefits}

\subsubsection{DG definition}

To get a definition for the DG, a short survey of the literature shows that there is no consensus. [3].

The IEEE defines DG the generation of electricity by facilities that are sufficiently smaller than central generating plants to allow interconnection at nearly any point in a power system [3].

The Electric Power Research Institute defines DG as generation from 'a few kilowatts up to $50 \mathrm{MW}$ ' [1].

In references [1-4], a large number of terms and definitions is used in relation to DG.

Different issues to get a common definition [1-4]:

Services supplied; the purpose of $D G$ is to provide a source of active electric power.

Voltage level (transmission/ distribution); most authors see DG as being connected to the distribution network, but some few authors allow DG to be connected to the transmission grid. The idea of being closely to the loads is more accepted without any distinction on the voltage levels.

Generation capacity (MW); the rating of DG is dependant of the capacity of the system it placed in. 
Power delivery area; some authors define the power delivery area, e.g. all power ge A. A. Abou ElEla, S. M. Allam and M. M. Shatla, "Maximal Optimal Benefits of Distributed Generation using Genetic Algorithms"nerated by DG is used within the distribution network. In certain circumstances, defining the power delivery area is not very helpful.

Generation technology; the term-DG often is used in combination with renewable energy technology [5]; however, the technology that can be used is not limited.

Environmental impact; often DG technologies are described as more environmentally friendly than centralized generation.

Mode of operation; DG is relatively unencumbered by the rules of operation of central systems (scheduling pool pricing, dispatch, etc.).

Ownership; DG may owned by Distribution companies, may owned by generation companies as the CHP and some traditional units and may owned by independent power producers or by the customers themselves.

From above; DG can be having a common definition as relatively small electric power generation compared to the system they are placed be connected to distribution networks or close to the customers' side

\subsubsection{DG major policy issues}

DG major policy issues can be summarized as:

- High financial cost; relatively high capital costs per $\mathrm{kW}$-installed power of DG compared to large central plants.

- System frequency deviation; the installations of DG increase the burden on the system operator to maintain the system frequency.

- Less choice between more costly primary fuels; Most DG technologies are based on gas.

- Voltage deviations; the connection of DG have a significant influence on the local voltage level, reference [6] discussed the impact of DG on the voltage profiles. This does not need to be a problem when the grid operator faces difficulties with low voltages.

- Change in power flow; an increased share of DG units may induce power flows from the low voltage into the medium-voltage grid.

- Bi-directional power flows; make it difficult to tune the protection systems in the grid. An' islanding' situation may occur.

- Lower reactive power; Medium-sized and especially small DG technologies often use asynchronous generators. These units are not capable of providing reactive power.

- Higher harmonics; Some DG technologies produce direct current. Thus, these units have to be connected to the grid via a $\mathrm{DC}-\mathrm{AC}$ interface, which may contribute to higher harmonics.

\subsubsection{Major benefits of DG}

Generally, the major DG benefits can be classified and summarized as:

\section{A. Composite technical and economic benefits (CB)}

- Standby capacity or peak use capacity; this leads to lower operating costs due to peak shaving. Furthermore, reduced reserve requirements and the associated costs. To serve loads in the event of sudden or unexpected failure of operating generating units, utilities must maintain some generation capacity as spinning reserve. Spinning reserve in a correct amount has an equivalent effect to load shedding in controlling frequency excursions [7].

- Reliability, security and power quality; in areas where voltage support is difficult, DG can contribute because connecting DG generally leads to a rise in voltage in the network. DG enhances the security of electric power supply.

B. Technical benefits (TB)

- Climate, environmental, and health concerns; an overall reduction of $\mathrm{CO} 2$-equivalent emissions up to $4 \%$ seems a technically feasible scenario [8]. In addition, DG reduces health care costs due to improved environment and reduces fuel costs due to increased overall efficiency [9].

- Grid support; stabilize a dropping frequency due to a sudden under capacity or excess demand.

\section{Economic benefits (EB)}

- Constraints on the construction of new transmission lines; DG acts as a bypass for transmission and distribution costs and for public opposition to building new transmission lines on environmental grounds. Moreover, well-chosen DG locations can also contribute to reduced grid losses.

- Developments in DG technologies; some DG technologies reduce operation and maintenance costs of the generation units.

Many researchers recently have studied DG sitting and sizing problems. In [10] an analytical method is proposed to determine the optimal location of DG to minimize the power loss of the system. In [11] the DG location problem was considered concerning the power loss and voltage drop using a multi-objective index. In [12], an optimal sitting was determined by sensitivity analysis of the power flow equations. An optimal DG size and sitting for optimizing system voltages was presented in [13]. Reference [14] presented a genetic algorithm based DG placement technique for minimizing the total power losses.

This paper proposes a flexible optimal approach to plan for maximization the required benefits from the DG, which may be one or a combination of attributes. 
The CB (voltage profile improvement (VPI) and spinning reserve increasing (SRI)) and EB (line loss reduction (LLR) and power flow reduction (PFR)) are optimized in this paper to reduce the voltage and frequency deviations.

The use of conventional linear programming (LP) technique has the popular one may use due to the simplicity of system modeling and objectives. The LP can be defined by an optimization of a linear objective functions and linear constraints. Some of LP applications are listed and reported as follow: Optimal power flow problems [15], Security control calculations and optimizations in references [16-18], Power dispatch problems and emergency control [19], Optimal preventive control actions [20].

\section{PROBLEM FORMULATION}

The optimal sitting and sizing for DG installations for maximum required benefits lead to the highest value of overall benefits of DG by achieving some objective functions with system constrains.

\subsection{Objective Functions}

By comparing and taking the ratio of a measure of an attribute with and without DG (with the loads served being the same), an index can be derived for any attribute:

\subsubsection{Single Objective optimizations}

\section{A. Voltage Profile Improvement (VPI)}

$$
\text { Max VPI } \%=\frac{\mathrm{VP}_{\mathrm{w} / \mathrm{DG}}-\mathrm{VP}_{\mathrm{wo} / \mathrm{DG}}}{\mathrm{VP}_{\mathrm{wo} / \mathrm{DG}}} * 100
$$

While the general expression for the voltage profile

$$
\begin{aligned}
& \text { (VP) is } \quad \mathrm{VP}=\sum_{\mathrm{i}=1}^{\mathrm{N}} \mathrm{V}_{\mathrm{i}} \mathrm{L}_{\mathrm{i}} * \mathrm{~W}_{\mathrm{vi}} \\
& \sum_{\mathrm{i}=1}^{\mathrm{N}} \mathrm{W}_{\mathrm{vi}}=1
\end{aligned}
$$

where:

VPI \% Percentage of voltage profile improvement.

$\mathrm{VP}_{\mathrm{W}} / \mathrm{DG} \mathrm{VP}$ index of the system with DG, pu.

$\mathrm{VP}_{\mathrm{wo}} / \mathrm{DG}$ Voltage profile index without DG, pu.

$\mathrm{V}_{\mathrm{i}} \quad$ Voltage magnitude at bus i.

$\mathrm{W}_{\mathrm{vi}} \quad$ Weighting factor for load bus i.

$\mathrm{L}_{\mathrm{i}} \quad$ Load at bus i, pu.

N Total buses number

\section{B. Total Spinning Reserve Increasing (SRI)}

$$
\operatorname{Max} \mathrm{SRI} \%=\frac{\mathrm{SR}_{\mathrm{w} / \mathrm{DG}}-\mathrm{SR}_{\mathrm{wo} / \mathrm{DG}}}{\mathrm{SR}_{\mathrm{wo}} / \mathrm{DG}} * 100
$$

However, the spinning reserve (SR) is given as:

$$
\begin{aligned}
& \mathrm{SR}_{\mathrm{w} / \mathrm{DG}}=\sum_{\mathrm{g}=1}^{\mathrm{NG}}\left(\mathrm{Pg}_{\mathrm{g}}^{\max }-\mathrm{pg}_{\mathrm{gw} / \mathrm{DG}}\right)+\sum_{\mathrm{d}=1}^{\mathrm{NDG}}\left(\mathrm{Pg}_{\mathrm{d}}^{\max }-\mathrm{pg}_{\mathrm{d}}\right) \\
& \mathrm{SR}_{\mathrm{wo} / \mathrm{DG}}=\sum_{\mathrm{g}=1}^{\mathrm{NG}}\left(\mathrm{Pg}_{\mathrm{g}}^{\max }-\mathrm{pg}_{\mathrm{gwo} / \mathrm{DG}}\right)
\end{aligned}
$$

Where,

SRI\% Percentage of total spinning reserve increase in the system due to introducing of DG.

$\mathrm{SR}_{\mathrm{w} / \mathrm{DG}}$ Spinning reserve with introducing of DG, pu.

$\mathrm{SR}_{\mathrm{wo} / \mathrm{DG}}$ Spinning reserve without DG, pu.

$\mathrm{Pg}_{\mathrm{g}}^{\max } \quad$ Maximum output power of the traditional power generation unit $\mathrm{g}$, pu.

$\mathrm{pg}_{\mathrm{gw} / \mathrm{DG}}$ Operating output power of traditional power generation unit $g$ with introducing of DG, pu.

$\mathrm{Pg}_{\mathrm{d}}^{\max }$ Maximum output power of the DG unit $\mathrm{d}$, pu.

$\mathrm{pg}_{\mathrm{gwdDG}}$ Operating output power of traditional power generation $g$ without introducing of DG, pu.

$\operatorname{pg}_{\mathrm{d}} \quad$ Operating output power of DG unit $\mathrm{d}$, pu.

$\mathrm{N}_{\mathrm{G}} \quad$ Total number of the traditional generation units

$\mathrm{N}_{\text {DG }} \quad$ Total number of the DG units

\section{Power Flow Reduction in Critical Lines (PFR)}

$$
\operatorname{Max} \mathrm{PFR} \%=\frac{\mathrm{PF}_{\mathrm{K}, \mathrm{wo} / \mathrm{DG}}-\mathrm{PF}_{\mathrm{K}, \mathrm{w}} / \mathrm{DG}}{\mathrm{PF}_{\mathrm{K}, \mathrm{wo}} / \mathrm{DG}} * 100
$$

With

$$
\begin{aligned}
\mathrm{PF}_{\mathrm{k}, \mathrm{w} / \mathrm{DG}} & =\sum_{\mathrm{k}=1}^{\mathrm{NL}} \mathrm{PF}_{\mathrm{k}, \mathrm{w} / \mathrm{DG}} * \mathrm{~W}_{\mathrm{pfk}} \\
\mathrm{PF}_{\mathrm{k}, \mathrm{wo} / \mathrm{DG}} & =\sum_{\mathrm{k}=1}^{\mathrm{NL}} \mathrm{PF}_{\mathrm{k}, \mathrm{wo} / \mathrm{DG}} * \mathrm{~W}_{\mathrm{pfk}}
\end{aligned}
$$

Where

PFR \% Percentage reduction in power flow due to DG.

$\mathrm{PF}_{\mathrm{k}, \mathrm{w} / \mathrm{DG}}$ Active power flow in line k with DG, pu. $\mathrm{PF}_{\mathrm{k}, \mathrm{wo} / \mathrm{DG}}$ Power flow in line $\mathrm{k}$ without using DG, pu.

$\mathrm{W}_{\text {pfk }} \quad$ Weighing factor for power flow in line $\mathrm{k}$.

NL Total transmission lines number.

\section{E. Total Line-loss Reduction (PFR)}

$$
\operatorname{Max} \mathrm{LLR} \%=\frac{\mathrm{LL}_{\mathrm{wo} / \mathrm{DG}}-\mathrm{LL}_{\mathrm{w}} / \mathrm{DG}}{\mathrm{LL}_{\mathrm{wo}} / \mathrm{DG}} * 100
$$

However, the transmission line-loss (LL) is given as

$$
\begin{aligned}
\mathrm{LL}_{\mathrm{w}} / \mathrm{DG} & =\sum_{\mathrm{k}=1}^{\mathrm{NL}} \mathrm{I}_{\mathrm{k}, \mathrm{w} / \mathrm{DG}}^{2} \mathrm{R}_{\mathrm{k}} \mathrm{D}_{\mathrm{k}} \\
\mathrm{LL}_{\mathrm{wo} / \mathrm{DG}} & =\sum_{\mathrm{k}=1}^{\mathrm{NL}} \mathrm{I}_{\mathrm{k}, \mathrm{wo} / \mathrm{DG}}^{2} \mathrm{R}_{\mathrm{k}} \mathrm{D}_{\mathrm{k}}
\end{aligned}
$$

where:

LLR Percentage reduction of line-loss due to DG. 
$\mathrm{LL}_{\mathrm{w}} / \mathrm{DG}$ Total line losses with employment of DG, pu.

$\mathrm{LL}_{\mathrm{wo}}$ / DG Line losses in the system without DG, pu.

$\mathrm{R}_{\mathrm{k}} \quad$ Line resistance for line $\mathrm{k}, \mathrm{pu} / \mathrm{km}$.

$\mathrm{D}_{\mathrm{k}} \quad$ Line length for line $\mathrm{k}, \mathrm{km}$.

$\mathrm{I}_{\mathrm{k}, \mathrm{w} / \mathrm{DG}} \quad$ Line current in line $\mathrm{k}$ with DG, pu.

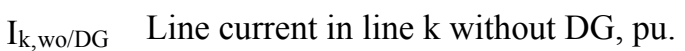

\subsubsection{Multi-Objectives Optimization (Composite Benefits)}

A multi-objective technique is used to optimize more than one objective function simultaneously.

A multi-objective optimization problem can be solved by using the weighting factors according to the planner selection for maximization the required composite benefits from DG.

The weight factors can be highly sensitive parameters. A small adjustment can lead to a large shift in performance of the optimal solution.

The overall maximal composite benefits of DG (OMBDG) can be formulated as:

$$
\begin{aligned}
& \text { OMBDG }=\mathrm{w}_{1} \mathrm{VPI} \%+\mathrm{w}_{2} \mathrm{SRI} \%+\mathrm{w}_{3} \mathrm{PFR} \%+\mathrm{w}_{4} \mathrm{LLR} \% \\
& \text { With } 0 \leq \mathrm{w}_{\mathrm{i}} \leq 1 ; \sum_{\mathrm{i}=1}^{4} \mathrm{~W}_{\mathrm{i}}=1 \text { and } \mathrm{i}=1, \ldots, 4
\end{aligned}
$$

where $\mathrm{w}_{1}, \mathrm{w}_{2}, \mathrm{w}_{3}$ and $\mathrm{w}_{4}$ are benefit weighting factors for $\mathrm{VPI} \%, \mathrm{SRI} \%, \mathrm{PFR} \%$ and LLR\% respectively .

The choice of weighting factors depends on the objective (merit) that required to be more mitigated. However, if DG is introduced to mitigate a certain objective to overcome a specific problem (such as voltage deviation or frequency deviation), then the corresponding index can be assigned for a greater weight factor as compared to other factors.

\subsection{System Constraints}

\subsubsection{The total DG number allowed:}

Maximum allowable number $\left(\mathrm{N}_{\mathrm{DG} / \mathrm{MAX}}\right)$ is limits the $\mathrm{DG}$ number $\left(\mathrm{N}_{\mathrm{DG}}\right)$ :

$$
\mathrm{N}_{\mathrm{DG}} \leq \mathrm{N}_{\mathrm{DG} / \mathrm{MAX}}
$$

\subsubsection{Traditional Generation capacity constraints}

For stable and secure operation, the value of real power output of each traditional generator using DG $\left(\mathrm{Pg}_{\mathrm{gw} / \mathrm{DG}}\right)$ is restricted by its lower and upper limits $\left(\mathrm{Pg}_{\mathrm{g}}^{\min } \& \mathrm{Pg}_{\mathrm{g}}^{\max }\right)$ respectively:

$\mathrm{Pg}_{\mathrm{g}}^{\min } \leq \mathrm{Pg}_{\mathrm{gw} / \mathrm{DG}} \leq \mathrm{Pg}_{\mathrm{g}}^{\max }$

\subsubsection{DG Generation capacity constraints:}

For stable and secure operation, the value of real power output of each DG $\left(\mathrm{Pg}_{d}\right)$ is restricted by its lower and upper limits $\left(\operatorname{Pg}_{d}^{\min } \& \operatorname{Pg}_{d}^{\max }\right)$, respectively:

$$
\operatorname{Pg}_{d}^{\min } \leq \operatorname{Pg}_{d} \leq \operatorname{Pg}_{d}^{\max }
$$

\subsubsection{Power balance constraint:}

The total power generation from traditional generations and DG units must cover the total load demand $\left(\mathrm{P}_{\mathrm{d}}\right)$ and the total real power losses (LL).

$$
\sum_{\mathrm{g}=1}^{N_{G}} \mathrm{Pg}_{\mathrm{gw} / \mathrm{DG}}+\sum_{\mathrm{d}=1}^{\mathrm{NDG}} \mathrm{Pg}_{\mathrm{d}}=\mathrm{P}_{\mathrm{d}}+\mathrm{LL}
$$

\subsubsection{Security constraints:}

The transmission line loading $\mathrm{PF}_{\mathrm{k}}$ is restricted by its upper limit $\left(\mathrm{PF}_{\mathrm{k}}^{\max }\right)$ as:

$$
\mathrm{PF}_{\mathrm{k}} \leq \mathrm{PF}_{\mathrm{k}}^{\max } \quad \mathrm{k}=1,2 \ldots \mathrm{NL}
$$

\subsubsection{Voltage limits constraints:}

The value of the bus voltage ( $\mathrm{Vi}$ ) is restricted by lower and upper limits for that $\mathrm{DG}\left(\mathrm{Vi}^{\mathrm{min}} \& \mathrm{Vi}^{\mathrm{max}}\right.$ ) as:

$$
\mathrm{Vi}^{\min } \leq \mathrm{Vi} \leq \mathrm{Vi}^{\max }
$$

\section{OPTIMAL PROPOSED APPROACH FOR MAXIMAL BENEFITS OF DG (MBDG)}

The Genetic Algorithms Optimization Technique (GA) is used for optimal proposed approach (OPA), in order to implement the search of the optimal solution. Because the GA needs scalar fitness information to work, it is natural to propose a combination of all the objectives into a single one, by using a weighted sum of the single objective functions. This methodology can be applied to generate non-dominated solution to be used as an initial solution [21].

\subsection{Genetic Algorithm (GA)}

Advantages GA are the ability to avoid being trapped in local optima, and the expected number of function evaluations before reaching the optimum is significantly reduced compared with exhaustive search methods [22].

GA is an optimization method that employs a search process imitated from the mechanism of biological selection and biological genetics [13].

The GA begins with a very large set of initial candidate solutions. These solutions are subjected to selection pressure based on relative fitness and other genetic operators that serve to advance in the search. Each candidate solution is known as a chromosome, and the set of all chromosomes is created from the previous set through the so-called genetic operators (crossover, mutation, etc.). In any generation, the fitness of each chromosome is defined in such a way that the chromosome with the highest fitness represents the optimal point in the search space. The higher fitness solution string has more probability to have more copies. This copying procedure is called 
"Selection" as shown in Fig.1.Under certain conditions; it has been proven that the average fitness improves from one generation to the next [15].

The "Crossover" takes two individuals and produces two new individuals, used for innovating the solution strings.

The "Mutation" alters one individual to produce a single new solution; it can help the solution strings to have a wider area of feasible solutions. After these three genetic operations, namely, Selection, Crossover and Mutation, the new generation solution strings exist. These new generation solution strings start the genetic operations repeatedly until the feasible solution is satisfied.

The process of optimal proposed approach for maximal benefit of DG (MBDG) is shown in Fig.2.

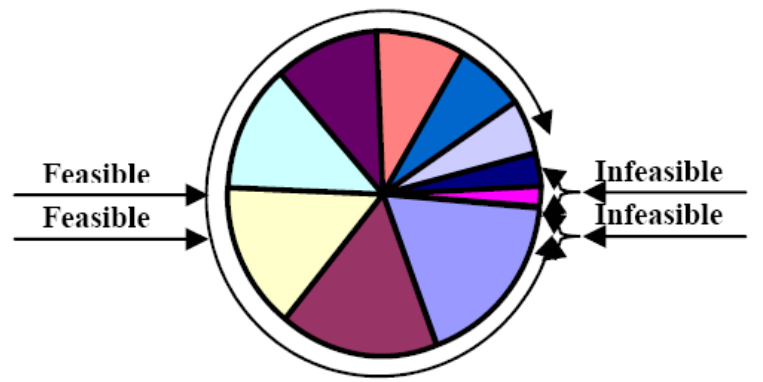

Fig. 1 Selection using Roulette wheel

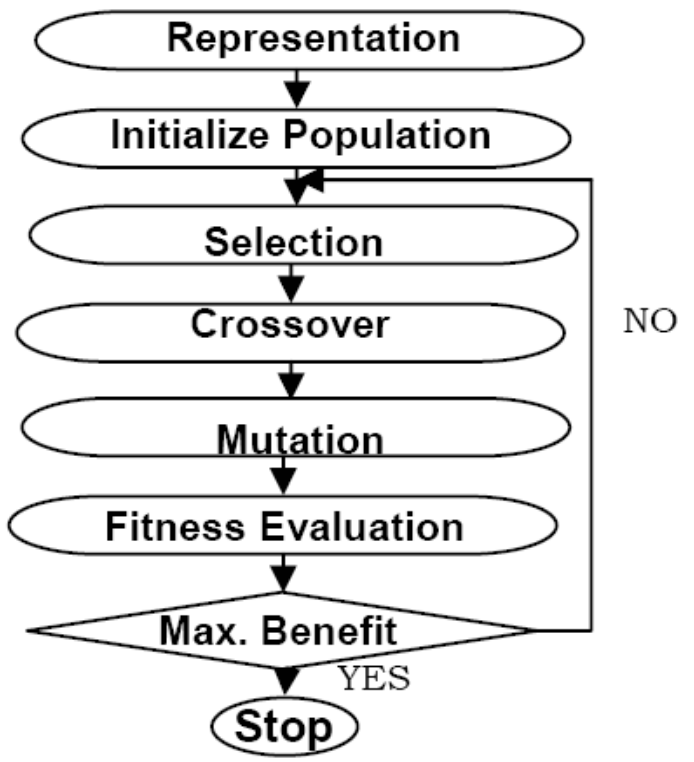

Fig. 2 Flowchart of MBDG

\subsection{Basic Parameters for MBDG}

Before running the OPA many parameters in GA need to be set, such as:

\section{- Population size (Pop)}

This is the number of chromosomes in a population, and describes the number of searching points. This factor is problem dependant, and must be increased with the increase in number of control variables.
- Number of populations, generations (Npop)

This is a sufficient number of iterations or populations that are required to get the optimal solution and it is used as a stopping criterion. The optimal solution may be obtained before reaching the number of populations.

\section{- Probability of crossover (Pc)}

This parameter is used to determine the number of chromosomes required to be included in the crossover process. Increasing this parameter increases the ability of GA to latch the global optimum solution.

- Probability of mutation (Pm)

The probability of mutation is usually small. The number of bits that undergo the mutation operation is determined by the mutation probability.

- Solution precession (Pr)

High precession increase the chromosome length and hence the computational time.

\subsection{Representation and Implementation of the Optimal Proposed Approach for MBDG}

A. State and power level of the DG

A string $G$ of 5 binary bits represents each generator. The first bit represents the state of the generator ( 1 for on, 0 for off). The remaining 4 bits represent the power level of the generator, situated between $1 / 16$ and $100 \%$. As an example, the string $\mathrm{G}=[1000]$ represents a generator working at minimum capacity; $\mathrm{G}=$ [00000] represents a generator which is not operating (or not existing); the string $G=[11111]$ represents a generator working at full capacity.

\section{B. Location of the DG}

As each string $\mathrm{G}$ represents the generator size to be placed at a given node, the representation of the general location of the generators over the grid is straightforward. A string $\mathrm{S}$ is defined consisting on the concatenations of $\left(\mathrm{G}^{*}\right.$ no. of nodes) strings. This sequence with eight nodes system; $\mathrm{S}$ contains eight $($ nodes $) \times 5$ (bits per node $)=40$ bits. As any string, $S$ describes a valid placement and size configuration of generators over the grid, therefore the string $\mathrm{S}$ is the chromosome used within the MBDG.

The implementation of MBDG with eight nodes system is done with generations consisting of 40 individuals (each one has a different string $\mathrm{S}$ ).

C. Fitness of the individuals (objective optimization with constraints)

The fitness of each individual is given by the objective function, and it considers a penalization if the constrains goes outside the allowed limits, plus another penalization if the number of generators exceeds a maximum number (is set to be 1.0). The fitness value $\mathrm{F}$ for any individual $\mathrm{S}$ is:

$\mathbf{F}(\mathbf{S})=$ objective $+\mathbf{C 1 Z 1}+\mathbf{C} 2 \mathrm{Z} 2+\mathbf{C} 3 Z 3+\mathbf{C} 4 \mathrm{Z4}+\mathbf{C} 5 Z 5+\mathbf{C 6 Z 6}$ Where: 
Objective; might be single or multi-objective function

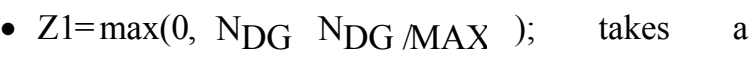
penalty $\mathrm{C} 1$ if the number $\mathrm{N}_{\mathrm{DG}}$ on solution $\mathrm{S}$ is larger than the maximum allowed number of $\mathrm{DG} \mathrm{N}_{\mathrm{DG} / \mathrm{MAX}}$.

- $\mathrm{Z} 2=\max \left(0, \mathrm{Pg}_{\mathrm{g}}^{\min }-\mathrm{Pg}_{\mathrm{gw} / \mathrm{DG}}\right)+\max \left(0, \mathrm{Pg}_{\mathrm{gw} / \mathrm{DG}}\right.$ $\left.-\mathrm{Pg}_{\mathrm{g}}^{\max }\right)$; takes a penalty $\mathrm{C} 2$ if the value of real power output of each traditional generator with introducing of DG $\left(\mathrm{Pg}_{\mathrm{gw} / \mathrm{DG}}\right)$ lies outside the limits.

- $\mathrm{Z} 3=\max \left(, \mathrm{Pg}_{\mathrm{d}}^{\min }-\mathrm{Pg}_{\mathrm{d}}\right)+\max \left(0, \mathrm{Pg}_{\mathrm{d}}-\mathrm{Pg}_{\mathrm{d}}^{\max }\right) ;$ take

$s$ a penalty $\mathrm{C} 3$ if the value of real power output of each

DG $\left(\mathrm{Pg}_{\mathrm{d}}\right)$ lies outside the limits

- $\mathrm{Z} 4=\max \left(0,\left(\sum_{\mathrm{g}=1}^{\mathrm{N}_{\mathrm{G}}} \mathrm{pg}_{\mathrm{gw} / \mathrm{DG}}+\sum_{\mathrm{d}=1}^{\mathrm{N} D G} \mathrm{pg}_{\mathrm{d}}\right)-\left(\mathrm{p}_{\mathrm{d}}+\mathrm{LL}\right)\right)$

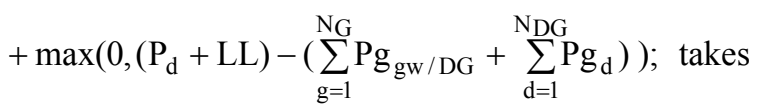

a penalty $\mathrm{C} 4$ if the total power generation from traditional generations and DG units did not cover $\left(\mathrm{P}_{\mathrm{d}}\right)$ and $(\mathrm{LL})$.

- $\mathrm{Z} 5=\max \left(0, \mathrm{PF}_{\mathrm{k}} \quad \mathrm{PF}_{\mathrm{k}}^{\max }\right)$; takes a penalty $\mathrm{C} 5$ if the transmission line loading $\mathrm{PF}_{\mathrm{K}}$ lies outside the limits.

- $\mathrm{Z} 6=\max \left(0, \mathrm{~V}_{\min }-\mathrm{V}_{\mathrm{i}}\right)+\max \left(0, \mathrm{~V}_{\mathrm{i}} \quad \mathrm{V}_{\max }\right)$; takes a penalty $\mathrm{C} 6$ if $\mathrm{V}_{\mathrm{i}}$ lies outside the limits.

\section{Constraints}

If any of the constraints lies outside the limits, Crossover is performed between individuals, which are selected with a probability depends on their fitness. Mutation takes place with probability 0.0035 for bit.

\section{APPLICATION}

\subsection{Test System}

The topology of an actual existing grid is used, as a part of West Delta network (WDN) that sometimes suffers from under voltage, overflows and frequency deviations due to insufficient power generation reserve. The configuration of this actual system is illustrated in Fig. 3. DG used are in tens of megawatts (up to $100 \mathrm{MW}$ ) because it most likely find their place in medium voltage sub-transmission systems. The main purposes of the OPA are to conclude how MBDG can be calculated and optimized.

The test system consists of 8-buses and 7transmission lines. All per-unit quantities used in this study are based on a 100-MVA. This system consists of one conventional generator located at bus 8 with rating of 2.5 p.u. Resistances, reactances and the lengths of all lines are listed in Table1. The loads are located unevenly on every bus as listed in Table 2.

The power flows are solved using MATPOWER and GA implemented inside MATLAB 6.5 are used to obtain the optimal sitting and sizing of DG.

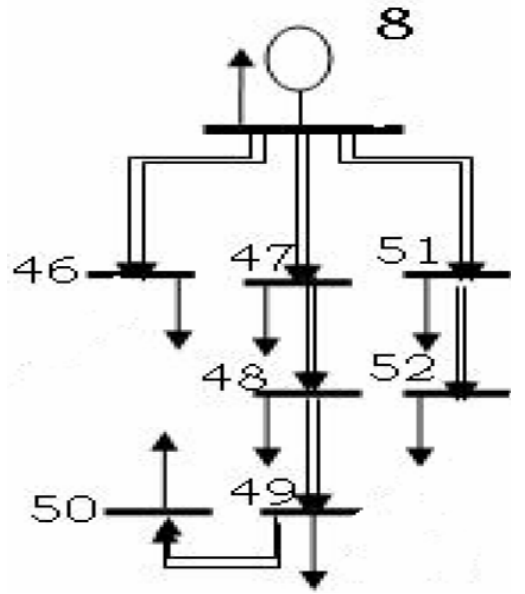

Fig. 3 Single-line diagram of the actual system under study

The influences of varying the sitting and sizing of DG are also investigated using LP in which three case studies are simulated for assessing MBDG, which are:

Case 1) DG located at bus 48.

Case 2) DG located at bus 50.

Case 3) DG located at bus 49.

Table 1 Actual Test System Line Data

\begin{tabular}{|c|c|c|c|c|c|}
\hline Line No. & From Bus & To Bus & Length(km) & R (pu) & X(pu) \\
\hline 1 & 8 & 46 & 26 & 0.126 & 0.365 \\
\hline 2 & 8 & 47 & 67 & 0.126 & 0.365 \\
\hline 3 & 8 & 51 & 55.68 & 0.076 & 0.35 \\
\hline 4 & 47 & 48 & 51 & 0.126 & 0.365 \\
\hline 5 & 48 & 49 & 36.36 & 0.126 & 0.365 \\
\hline 6 & 49 & 50 & 15 & 0.076 & 0.35 \\
\hline 7 & 51 & 52 & 47 & 0.076 & 0.35 \\
\hline
\end{tabular}

Table 2 Bus Loads Data and the Assumed Bus Weighting Factors sets

\begin{tabular}{|c|c|c|c|c|c|}
\hline Bus no. & Bus load & $\mathbf{W}_{\mathbf{v} 1}$ & $\mathbf{W}_{\mathbf{v} 2}$ & $\mathbf{W}_{\mathbf{v} 3}$ & $\mathbf{W}_{\mathbf{v} 4}$ \\
\hline 8 & 0 & 0 & 0 & 0 & 0 \\
\hline 46 & 0.2038 & 0.1428 & 0.1469 & 0.1421 & 0.1445 \\
\hline 47 & 0.192 & 0.1428 & 0.1413 & 0.1431 & 0.1422 \\
\hline 48 & 0.096 & 0.1428 & 0.0718 & 0.1547 & 0.1132 \\
\hline 49 & 0.2158 & 0.1428 & 0.1550 & 0.1408 & 0.1479 \\
\hline 50 & 0.1500 & 0.1428 & 0.1081 & 0.1486 & 0.1284 \\
\hline 51 & 0.0713 & 0.1428 & 0.0369 & 0.1605 & 0.0987 \\
\hline 52 & 0.4713 & 0.1428 & 0.3398 & 0.1100 & 0.2249 \\
\hline
\end{tabular}

\subsection{Results and Discussion of VPI\%}

Bus weighting factors are significant in determining VPI.. To study their impact, four sets of bus weighting factors (sets 1 through 4 ), as listed in Table 2, are used to quantify (VPI \%). The four sets are $\mathrm{W}_{\mathrm{v} 1}$ (for equal weights), $\mathrm{W}_{\mathrm{v} 2}$ (takes large values for heavily load buses), $\mathrm{W}_{\mathrm{v} 3}$ (takes large values for 
light load buses) and $\mathrm{W}_{\mathrm{v} 4}$ (is the average between $\mathrm{W}_{\mathrm{v} 2} \& \mathrm{~W}_{\mathrm{v} 3}$ ). However, voltages at heavy load buses, before introducing of DG (base case), are relatively low compared to the light load buses. Therefore, VPI at heavily load buses with the introducing of DG is much significant more than at light load buses. Hence, the VPI\% with bus weighting factor set $\mathrm{W}_{\mathrm{v} 2}$ has the largest value compared to others.

Table 3 gives the optimal sitting and sizing of DG to obtain MBDG for VPI\%. In this table, VPI\% has the maximum value using the OPA (24.41) compared o the LP technique (24.26). However, bus 50 is the optimal sitting of DG rating $0.31 \mathrm{pu}$ to obtain MBDG for $\mathrm{VPI} \%$.

The variations of VPI\% with DG sizing for different sets of weighting factors using LP are shown in Fig. 4.

Table 3 MBDG Outputs for VPI:

\begin{tabular}{|c|c|c|}
\hline Results & GA & LP \\
\hline Optimal Sitting & Node 50 & Node 50 \\
\hline Optimal DG Sizing & 0.3105 & 0.300 \\
\hline Weighting & $\mathrm{W}_{\mathrm{v} 2}$ & $\mathrm{~W}_{\mathrm{v} 2}$ \\
\hline VPI \% & 24.41 & 24.26 \\
\hline
\end{tabular}

Fig. 5 shows the influence of DG sizing and sitting on VPI \% using LP in the study cases giving the optimal sitting among the studied cases result in MBDG to maximize VPI\% using LP, which is bus number 50 (case2), which is identical to GA results.

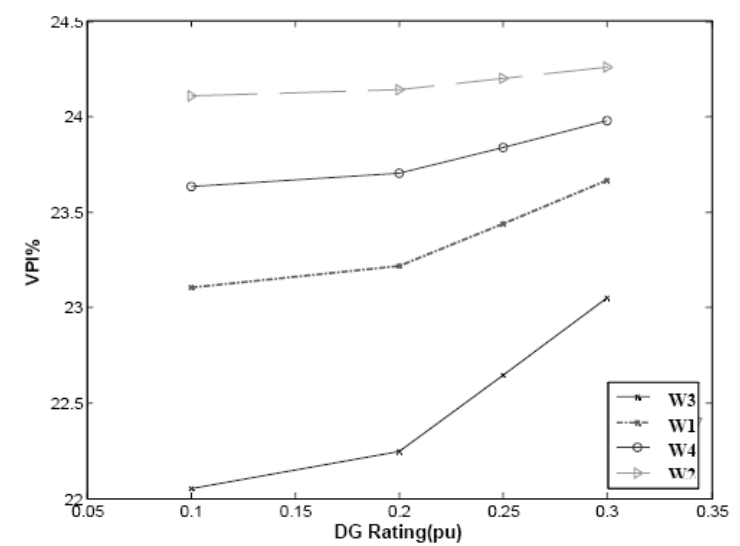

Fig. 4 Influence of DG sizing and bus weighting factors on $\mathrm{VPI} \%$ using LP

\subsection{Results and Discussion of SRI}

Table 4 gives the optimal sitting and sizing of DG to obtain MBDG for increasing SR\%. However, bus 50 is the optimal sitting of DG with rating equal to $0.31 \mathrm{pu}$. The $\mathrm{SRI} \%$ has a maximum value (63.1) compared to LP (63.075).

Fig. 6 gives the corresponding performance of GA to obtain MBDG for SRI\% using OPA.

Fig. 7 shows the influence of DG sitting and sizing on the SRI \% using LP.

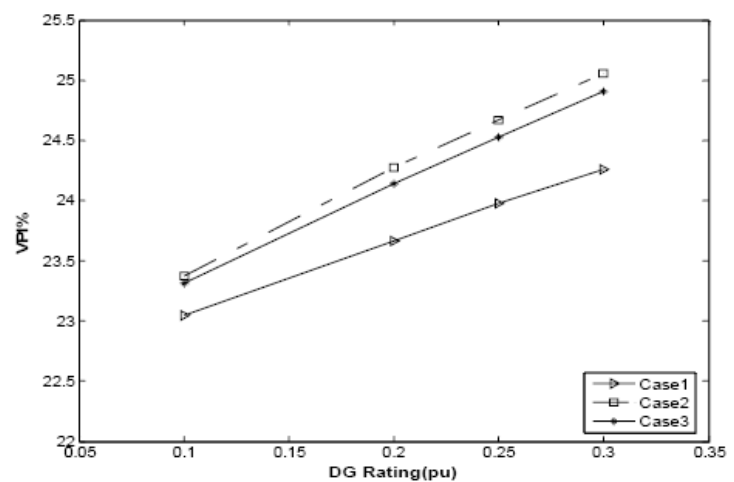

Fig. 5 Influence of DG sizing and sitting on VPI\% using LP

Table 4 MBDG Outputs for SRI\%:

\begin{tabular}{|l|c|c|}
\hline Results & OPA & LP \\
\hline Optimal Sitting & Node 50 & Node 50 \\
\hline Optimal DG Sizing (pu) & 0.3105 & 0.3000 \\
\hline Conventional generation (pu) & 1.10 & 1.111 \\
\hline SRI\% & 63.100 & 63.075 \\
\hline
\end{tabular}

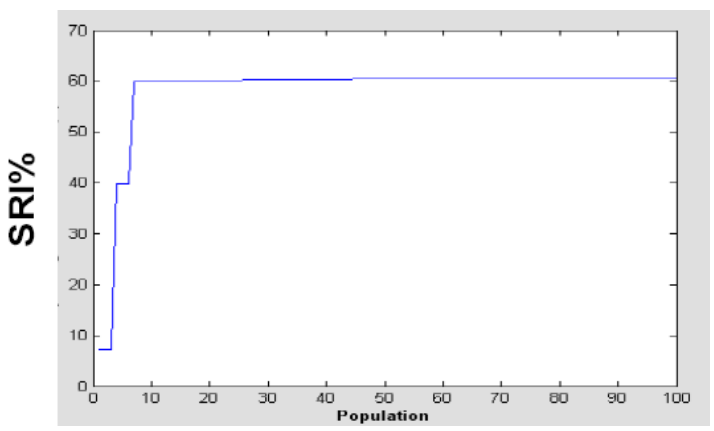

Fig. 6 GA performance to obtain max SRI\%

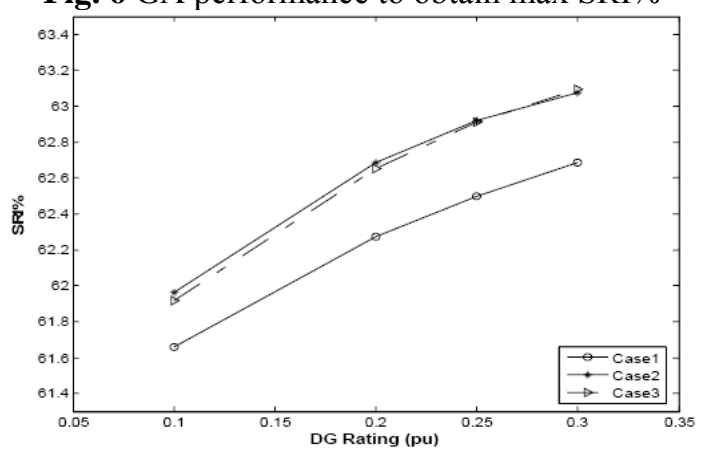

Fig. 7 Influence of DG sizing and sitting on SRI\% using LP

\subsection{Results and discussion of PFR}

Table 5 shows the power flow in each line without introducing DG and the corresponding weighting factors $\left(\mathrm{W}_{\mathrm{pfk}}\right)$. However $\mathrm{W}_{\mathrm{pfk}}$ take the large values for heavily line flows.

Table 6 shows the MBDG to increase the security margin for the critical lines (PFR\%). However, bus 50 is the optimal sitting of DG with rating equal to $0.31 \mathrm{pu}$ to obtain $\mathrm{MBDG}$ for $\mathrm{PFR} \%$ equal to (42.0156) to maximize the security margin. 
Table 5 Power flows without DG and their corresponding weighting factors

\begin{tabular}{|c|c|c|}
\hline From Bus to Bus & $\mathrm{PF}_{\mathrm{k}, \mathrm{wo} / \mathrm{DG}}$ & $\mathrm{W}_{\mathrm{pfk}}$ \\
\hline $8-46$ & 0.20668 & 0.067725 \\
\hline $8-47$ & 0.74803 & 0.24512 \\
\hline $8-51$ & 0.57084 & 0.18706 \\
\hline $47-48$ & 0.50678 & 0.16606 \\
\hline $48-49$ & 0.38252 & 0.12535 \\
\hline $49-50$ & 0.15166 & 0.049698 \\
\hline $51-52$ & 0.4852 & 0.15899 \\
\hline
\end{tabular}

Table 6 GA output for MBDG to maximize $\mathrm{PFR} \%$ :

\begin{tabular}{|l|l|l|}
\hline Results & OPA & LP \\
\hline Optimal Sitting & Node 50 & Node 50 \\
\hline Optimal DG Sizing (pu) & 0.310 & 0.300 \\
\hline Max PFR\% & 42.01 & 40.70 \\
\hline
\end{tabular}

Fig.8 shows the corresponding performance of GA to obtain the MBDG for PFR\%. From this Fig., the values of $\mathrm{DG}$ and conventional power generations outputs are 0.31 and 1.1 p.u. respectively.

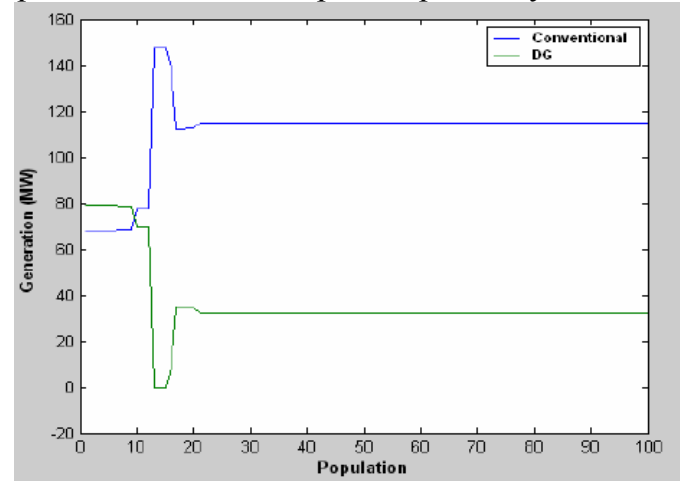

Fig. 8 GA performance giving DG and convention generation outputs to maximize $\mathrm{PFR} \%$

Fig.9 shows the influence of DG sitting and sizing on $\mathrm{PFR} \%$ using LP in the case studies giving the optimal sitting to obtain MBDG for increase the security margin, which is bus number 50 (case2), which is identical to GA results.

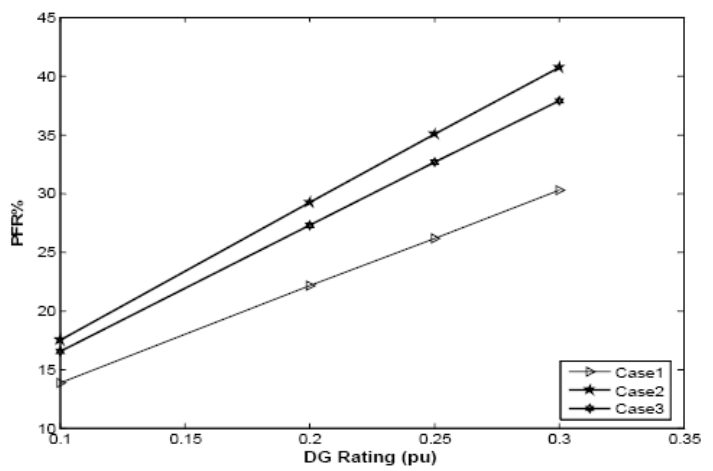

Fig. 9 Influence of DG sizing and sitting on PFR\% using LP

\subsection{Results and Discussion of LLR:}

Table 7 shows the optimal sitting and sizing of DG to obtain MBDG for LLR\%. However, bus 50 is the optimal sitting of DG with rating equal to 0.310 to decrease the line losses. This optimal sitting and sizing DG decrease the total line losses by $(81.5 \%)$ using OPA compared to (80.7\%) using LP technique.

Table 7 MBDG Outputs for LLR:

\begin{tabular}{|c|c|c|}
\hline Results & OPA & LP \\
\hline Optimal Sitting & Node 50 & Node 50 \\
\hline Optimal DG Sizing & 0.310 & 0.300 \\
\hline LL $_{\text {w/DG }}(\mathrm{pu})$ & 0.0256 & 0.0267 \\
\hline LL $_{\text {wo } / \mathrm{DG}}(\mathrm{pu})$ & 0.13855 & 0.13855 \\
\hline LLR $\%$ & 81.5 & 80.7 \\
\hline
\end{tabular}

Fig. 10 shows the influence of DG sitting and sizing on LLR\% using LP for different case studies. From this Fig., bus 50 is the optimal sitting of DG to obtain the MBDG for LLR\%.

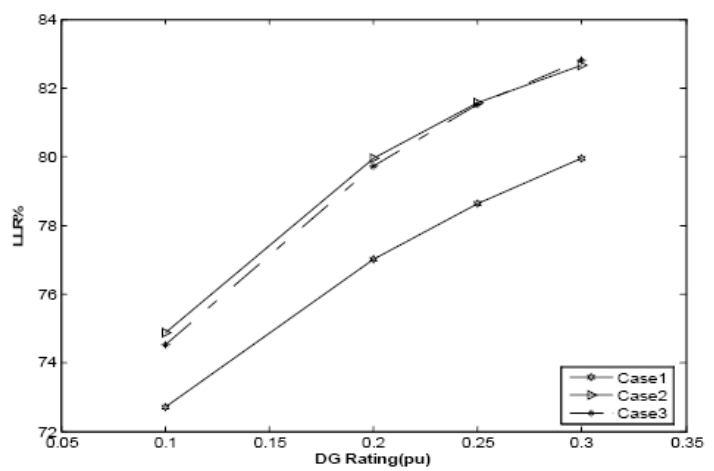

Fig. 10 Influence of DG sizing and sitting on LLR\% using

\subsection{Results and Discussion of Multi-objective} optimization (DG Composite Benefits)

The MBDG for VPI\%, SRI\%, PFR\% and LLR\% are achieved using the multi-objective functions which shown in equation (21). Assuming all benefit weighting factors (w1-w4) are equals.

Table 8 shows MBDG for VPI\%, SRI\%, PFR\% and LLR\%. Also from this table, the overall MBDG are obtained using OPA (81.5) compared to LP (80.7).

Table 8 MBDG using multi-objective functions

\begin{tabular}{|c|c|c|c|c|}
\hline Technique & VPI\% & SRI\% & PFR\% & LLR \% \\
\hline OPA & 24.26 & 63.100 & 42.0156 & 81.5 \\
\hline LP & 24.41 & 63.075 & 40.709 & 80.7 \\
\hline
\end{tabular}

Fig. 11 shows the influence of DG sizing on various DG benefits using LP for DG sitting at bus 50. From Table 8 and Fig. 11, it can be seen that the DG has the great influence on (LLR\%) and (SRI\%) more than (PFR\%) and (VPI\%).

Table 9 shows the optimal sitting and sizing of DG to obtain MBDG for maximal DG overall composite 
benefits. However, bus 50 is the optimal sitting of DG with rating equal to $0.3105 \mathrm{pu}$.

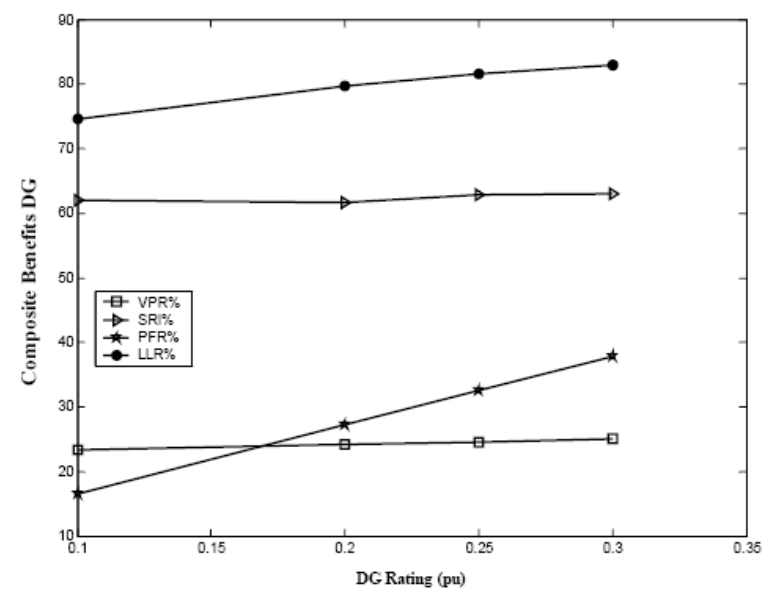

Fig. 11 Variations of various DG benefits with DG sizing for case

Table 9 MBDG for DG overall composite benefits:

\begin{tabular}{|c|l|l|}
\hline Results & OPA & LP \\
\hline Optimal Sitting & Node 50 & Node \\
\hline Optimal DG Sizing (pu) & 0.31 & 0.30 \\
\hline Overall Composite & 52.7 & 52.2 \\
\hline
\end{tabular}

\section{CONCLUSION:}

An optimization approach has been proposed to maximize the benefits with introducing DG using GA by chosen the optimal sitting and sizing of DG. Multi-objectives technique has been successfully applied to achieve four objective-functions simultaneously dependent on the choice of their weighting factors. The results have been confirmed by LP as a conventional technique, which is used also to demonstrate the influence of DG sitting and sizing on the benefits. The proposed approach has applied efficiency to subsets of DG benefits, which are voltage profile improvement (VPI), spinning reserve increasing (SRI), power flow reduction (PFR) and line loss reduction (LLR).

Simulation results obtained using actual system clearly show that DG has a great influence on VPI, SRI, PFR and LLR which has been assigned as DG benefits.

It has deducted that DG sizing plays a vital role in determining the amount of VPI, SRI, LLR and PFR.

The sitting of DG is also significant to DG benefits.

DG sizing has a major effect more than the DG sitting.

However, it should be noted that sitting and sizing of DG have only a minor impact on VPI and PFR as compared to SRI and LLR. Therefore, the choice of higher weighting factor for LLR and SRI yields the highest overall composite benefits.

\section{REFERENCES}

[1] T. Ackermann et al. "Distributed generation: a definition" Electric Power Systems Research 57 (2001) 195-204.

[2] Rob van Gerwent KEMA Nederland B.V. "Distributed Generation and Renewables, Introduction" Power Quality and Utilisation Guide November 2006

[3] G. Pepermans et al. "Distributed generation: definition, benefits and issues" Energy Policy 33 (2005) 787-798

[4] Chiradeja And Ramakumar "An Approach To Quantify The Technical Benefits Of DG" IEEE Transactions On Energy Conversion, Vol. 19, No. 4, December 2004

[5] Maurits van Laarhoven "Power Quality \& Utilization guide section 8: Distributed Generation, Standards"www.leonardoenergy.org January 2007

[6] Oscar E. Moya, Senior Member, IEEE "Numerical Tools and Models for Monte Carlo Studies of the Influence on Embedded Generation on Voltage Limits in LV Grids" IEEE Transactions On Power Delivery, Vol. 20, No. 3, JULY 2005

[7] Fabrice Demailly, Olivier Ninet, and André Even, Associate Member, IEEE "A Spinning Reserve, Load Shedding, and Economic Dispatch Solution by Bender's Decomposition " IEEE Transactions On Power Systems, Vol. 20, No. 1, FEBRUARY 2005

[8] D. Haeseldonckx, W. D'haeseleer “The Environmental Impact of Decentralized Generation in an Overall System Context" Renewable and Sustainable Energy Reviews

[9] E.J. Honton ":Increasing Power Reliability via Distributed Generation" Power Quality 2000 October 5, 2000ejh@or.rdcnet.com www.distributed-generation.com

[10] Caisheng Wang, Student Member, IEEE, and M. Hashem Nehrir, Senior Member, IEEE "Analytical Approaches for Optimal Placement of Distributed Generation Sources in Power Systems" IEEE Transactions On Power Systems, Vol. 19, No. 4, November 2004

[11] Luis F. Ochoa, Student Member, IEEE, Antonio Padilha-Feltrin, Member, IEEE, and Gareth P. Harrison, Member, IEEE ” Evaluating Distributed Generation Impacts with a multiobjective Index" IEEE Transactions On Power Delivery, Vol. 21, NO. 3, JULY 2006

[12] J. A. Greatbanks, D. H. Popovi'c, M. Begovi'c, A. Pregelj and T. C. Green" On Optimization for Security and Reliability of Power Systems with Distributed Generation"2003IEEE Bologna 
Power Tech Conference, June 23th-26th, Bologna,Italy

[13] D.T. Le, M.A. Kashem, M.Negnevitsky School of Engineering, University of Tasmania and G. Ledwich Electrical and Electronic Systems Engineering ,Queensland University of Technology Brisbane, Australia "Minimizing Voltage Deviation in Distribution Feeders by Optimizing Size and Location of Distributed Generation"g.ledwich@qut.edu.au

[14] Mithulananthan, Than Oo and Le Van Phu Electric Power System Management, Energy Program, Asian Institute of Technology Distributed Generator Placement in Power Distribution System Using Genetic Algorithm to Reduce Losses" Thammasat Int. J. Sc. Tech., Vol. 9,No. 3, July-September 2004

[15] A. A. Abou Ela, "Security Assessment in Power System Operation", Thesis of Doctor in Electrical Power Engineering, Minfioua University, Shebin El-Kom, 1983.

[16] B. Stott and E. Hobson, "Power System Security Control Calculations Using Linear Programming, Part II and I", IEEE Trans. on Power Systems, Vol. PAS - 97, Sept. / Oct. 1978 , pp. $1713-1731$.

[17] K. Tomosovic, and M. Y. Chow, "Tutorial on Fuzzy Logic Applications in Power Systems", IEEE- PES Winter Meeting, Singapore, January 2000
[18] K. Y. Lee and M. A. El-Sharkawi, "Modern Heuristic Optimization Techniques with Applications to Power Systems", New Intelligent Systems Technologies Working Group Intelligent System Applications Subcommittee Power System Analysis, Computing, and Economics Committee IEEE Power Engineering Society, 2000, available from site:www.ee.Washington.edu.

[19] Hai Fang Wang, H. Li, and H. Chen, "Coordinates Secondary Voltage Control to Eliminate Voltage Violation in Power System Contingencies", IEEE Trans. on Power Systems, Vol.18, No.2, May 2003, pp. 588-595.

[20] G. Xiaohong, W. H. E. Liu, and A.D. Papalexopoulos, "Application of a Fuzzy Set Method in an Optimal Power Flow", Electric Power Systems Research, Vol. 34, No. 1, May1995, pp. 11-18.

[21] G. Celli, E. Ghiani, S. Mocci, F. Pilo "A Multiobjective Formulation for the optimal Sizing and Sitting of Embedded Generation in Distribution Network" 2003 IEEE Bologna Power Tech Conference

[22] Edwin Haesen1, Marcelo Espinoza, Bert Pluymers, Ivan Goethals, Vu Van Thong, Johan Driesen, Ronnie Belmans, Bart De Moor "Optimal Placement and Sizing of Distributed Generator Units using Genetic Optimization Algorithms" Kasteelpark Arenberg 10, B-3001 Leuven (Heverlee), Belgium May 2, 2005 